\title{
Population Health Intervention Research Initiative for Canada: progress and prospects
}

\author{
Penelope Hawe ${ }^{\mathrm{A}, \mathrm{E}}$, Stephen Samis ${ }^{\mathrm{B}}$, \\ Erica Di Ruggiero ${ }^{\mathrm{C}}$ and Jean A. Shoveller ${ }^{\mathrm{D}}$ \\ ${ }^{\mathrm{A}}$ Population Health Intervention Research Centre, \\ University of Calgary, Canada \\ ${ }^{\mathrm{B}}$ Formerly, Heart and Stroke Foundation for Canada, \\ now Canadian Health Services Research Foundation \\ ${ }^{\mathrm{C}}$ Institute of Population and Public Health, \\ Canadian Institutes of Health Research \\ ${ }^{\mathrm{D}}$ School of Population and Public Health, \\ University of British Columbia \\ ${ }^{\mathrm{E}}$ Corresponding author.Email: phawe@ucalgary.ca
}

\begin{abstract}
Actions in Canada are being designed to transform the way research evidence is generated and used to improve population health. Capacity is being built in population health intervention research. The primary target is more understanding and examination of policies and programs that could redress inequities in health. The Population Health Intervention Research Initiative for Canada is a loosely-networked collaboration designed to advance the science of the field as well as the quantity, quality and use of population health intervention research to improve the health of Canadians. In the first few years there have been new training investments, new funding programs, new working guidelines for peer review, symposia and new international collaborations. This has been brought about by the strategic alignment of communication, planning and existing investments and the leveraging of new resources.
\end{abstract}

System-level change processes embed and become successful when the motives and perceived benefits of different people, organisations and processes harmonise. This paper describes how such an alignment of interests was achieved in the population health intervention research field in Canada and the strategies that are now taking it forward. The Population Health Intervention Research Initiative for Canada is a collaboration of research funders, non-governmental organisations, policy makers, researchers and trainees trying to shift the knowledge base for population and public health from a system that currently privileges description and analysis of health problems to one that caters more strongly to identifying and studying the outcomes of the policies and programs that will reduce health problems and health inequities and embed these into everyday practice. This paper outlines progress to date and new horizons for action.

\section{Impetus and early development of the Population Health Intervention Research Initiative for Canada}

Canada has a strong history in population and public health. Some of the best known outputs include the work produced under the rubric of the Canadian Institute for Advanced Research program on population health in a 10-year period spanning the 1980s and 1990s. The Institute is an interdisciplinary private not-for-profit research institute that provides leading scholars with the time, direction, freedom and inspiration to pursue fundamental questions concerning society, technology and the very nature of humanity and the universe. ${ }^{1}$ The population health program yielded outputs that were highly successful in reframing mainstream thinking about health (particularly that seen in government documents) and for putting social determinants of health into prominence. ${ }^{2,3}$

While not without its critics, ${ }^{4,5}$ the program was pivotal in generating funding and institutional structures to facilitate population and public health research. For example, federal funding for the Canadian Population Health Initiative, based within the Canadian Institute for Health Information (1999), helped to ensure that population health had a strong presence when Canada's Medical Research Council was redesigned as the Canadian Institutes of Health Research in 2000. Population and public health became the strategic focus of one of the 13 virtual institutes, the Institute of Population and Public Health. The field of social, cultural, environmental and population health was also made one of the four 'pillars' for categorising research across the Canadian Institutes of Health Research. The other three pillars are biomedical research, clinical research and health services research. The mission of the Institute of Population and Public Health is to improve the health of populations and promote health equity in Canada and globally by supporting research and encouraging its application to policies, programs and practices in public health and other sectors through strategic research investments. It also acts as a resource, guide and catalyst on population health research to the other Institutes and the Canadian Institutes 


\section{Box 1. Brief guide to some key pan-Canadian health agencies}

\begin{tabular}{|c|c|}
\hline Canadian Institutes of Health Research & $\begin{array}{l}\text { The main health research funding agency (like Australia's National Health and } \\
\text { Medical Research Council). Seventy percent of funds are for open competition } \\
\text { whereas } 30 \% \text { are for strategic initiatives including but not limited to funding } \\
\text { competitions in priority areas set by } 13 \text { Institutes (each with a Scientific Director, } \\
\text { an Institute Advisory Board and Institute staff). }\end{array}$ \\
\hline Canadian Institute for Health Information & $\begin{array}{l}\text { An independent, not-for-profit organisation that provides essential information } \\
\text { on Canada's health system and the health of Canadians (like the Australian } \\
\text { Institute of Health and Welfare). }\end{array}$ \\
\hline Canadian Population Health Initiative & $\begin{array}{l}\text { An arm of the Canadian Institute for Health Information established to improve } \\
\text { public understanding of population health and to contribute to policy making } \\
\text { to reduce health inequities and improve health. Focus is on knowledge } \\
\text { generation, synthesis, reporting and exchange. }\end{array}$ \\
\hline Public Health Agency of Canada & $\begin{array}{l}\text { Responsible for: promoting health; preventing and controlling disease and injury; } \\
\text { preparing for and responding to public health emergencies; and strengthening } \\
\text { public health capacity. }\end{array}$ \\
\hline
\end{tabular}

of Health Research as a whole. Box 1 explains the panCanadian health agencies in Canada referred to in this article.

The Population Health Intervention Research Initiative for Canada grew out of a meeting of key people and organisations held in Banff in September 2006 which noted that, within the Canadian public and population health research context, sophisticated analytic descriptions of increasingly sick populations receive emphasis (some might say too much emphasis). Insufficient attention, however, was being given to interventions to improve population health. This tendency had also been observed in the United Kingdom. ${ }^{6}$ A 2001-2006 review of grants awarded at the Canadian Institutes of Health Research showed that only $6 \%$ evaluated the impact of policies or programs to improve health. ${ }^{7}$ The Population Health Intervention Research Initiative for Canada was established to increase the quantity and quality of use of population health intervention research, as well as to align and embed activities supporting this across the knowledge production and knowledge use system.

Population health intervention research is defined as the use of scientific methods to produce knowledge about policy and program interventions that operate within or outside the health sector and have the potential to impact health at the population level. ${ }^{8}$ Impact at the population level does not only mean improving health or reducing health risks; it also means designing/implementing interventions which change the conditions of risk in order to shift the distribution of health risk, ${ }^{9}$ in keeping with the ideas of Geoffrey Rose. ${ }^{10}$ To be truly effective, a population health intervention should reduce risk exposure in successive cohorts of people within the setting(s) under investigation. Thus, as well as population health intervention research being an umbrella term that incorporates fields like health promotion research, health impact assessment, policy analysis and evaluation research, population health intervention research is designed to improve understanding of interventions addressing 'upstream' determinants of health, where some of the greatest long term gains may be realised.

A special supplement of the Canadian Journal of Public Health in 2009 documented the purpose of the Population Health Intervention Research Initiative for Canada, the rationale and the collaborating partners. ${ }^{7,11-16}$ This represented championship at the level of provincial health delivery systems, pan-Canadian health research agencies, university-based researchers, non-governmental organisations, and support at the Public Health Agency of Canada.

\section{Strategies and actions to support intervention research production and use}

The Population Health Intervention Research Initiative for Canada is stewarded by a planning committee made up of non-governmental organisations, health research funding agencies, researchers and public health policy makers and delivery organisations. It meets twice a year. The strategic plan encompasses four areas (Box 2).

The fundamental strategy is to work systematically on both the 'demand' and 'supply' sides of the population health intervention research equation, creating activities that increase the capacity to fund (e.g. operating grants and peer review guidelines) and conduct (e.g. training) population health intervention research as well as activities that encourage uptake and use, such as requirements for researcher-policy maker partnerships in knowledge production.

Population Health Intervention Research Initiative for Canada meetings provide opportunities to brainstorm 
Box 2. Population Health Intervention Research Initiative for Canada: strategic objectives

1. Advance the science of population health intervention research.

2. Strengthen Canada's capacity to conduct and use relevant population health intervention research for policy and practice.

3. Enhance Canada's contribution to the global knowledge base on population health interventions through continuous learning and international collaborations.

4. Champion population health intervention research and enhance its profile and usefulness.

new ideas and to align activities within each organisation in ways that maximise synergy and benefits. The Population Health Intervention Research Initiative for Canada is not an organisational structure that makes research funding decisions or develops Requests for Applications. The strategy is more high level and horizontal (e.g. planning symposia and communication tools, identifying infrastructure gaps, and alignment of activity where there is mutual interest). The Population Health Intervention Research Initiative for Canada (PHIRIC) has catalysed work on new criteria for peer review of intervention research to allow greater consideration of process evaluation as well as the relevance of the intervention to the population group. PHIRIC has also been a forum where agencies have reported on their own initiatives in line with PHIRIC objectives. An example is the Public Health Agency of Canada which has guided the focus of their investments away from smaller grants dispersed widely, towards larger targeted grants in priority areas (mental health promotion and obesity). This, along with new funding guidelines and procedures, has allowed for the development and testing of promising innovations and the building of stronger data systems to track and sustain them (Box 3).

PHIRIC is not a research or training body itself - it is a collaboration and coordination mechanism. While catalysed and supported by the Canadian Institutes of Health Research's Institute of Population and Public Health (which provides the secretariat functions), the key strength of PHIRIC is that it 'belongs' to no particular organisation and has no earmarked special funding. Rather, PHIRIC is about levering and growing commitments towards population health intervention research in participating organisations' own budgets, in various ways, organically. For example, the PHIRIC definition for population health intervention research has been adopted into numerous Requests for Applications across multiple agencies. The peer review guidelines have been designed and tested collaboratively across key agencies, also with the view to wide uptake upon completion.

An economic evaluation on the return on investment in PHIRIC operations has conservatively estimated that for every dollar invested, that is, direct and indirect costs of the secretariat and in terms of the key participating people and organisations (including travel and meeting costs for the planning committee, symposia/events, consultancy advice, administration and communication functions and people's time attending meetings and working on key tasks), another $\$ 30$ is being leveraged for packages of intervention research and training across Canada within the participating key agencies. These are for a broad range of beneficiaries, of the kind illustrated in Box $3 .{ }^{17}$

\section{Growth and new horizons}

PHIRIC has moved through the classic, 'text book' stages of collaborative problem-solving over time. ${ }^{18}$ At the beginning, the focus had to be on getting the 'right' organisations assembled, relying on broad and undifferentiated structures for engagement so as to maximise information exchange and identify common values. ${ }^{18}$ After the mission was identified and the tasks were set, different structures allowed for more focused, efficient, coordinated workflow (e.g. working groups). ${ }^{18}$ PHIRIC now has working groups in training, communication, evaluation and peer review. For example, the Evaluation Working Group will be collecting data that will allow us to assess: the leadership and championship role of population health intervention research at an organisational and system level; the extent to which there have been changes in the appraisal and support of evaluation of funding population health intervention studies; and the evaluation of training in population health intervention research, evaluation and knowledge exchange. The Training Working Group is pooling ideas and refining ways of measuring population health intervention research competencies. The Communication Working Group is designing fact sheets, webinars, case studies and a video.

Participation within the PHIRIC planning committee will be reviewed as activities grow and new constituencies form as a consequence. For example, right now there is no organised group of population health intervention research scientists in Canada, and so the researchers who happened to have been involved in PHIRIC's early development bore no formal communication responsibility or representational accountability to their peers. This is likely to change with symposia, publications and granting rounds now bringing the field into stronger definition.

Next steps for PHIRIC are about connecting more broadly with the intervention research in sectors other than health, and the researchers conducting it. In a nascent field like population health intervention research, we need to appreciate which words and phrases about evaluation research and integrated evidence into policy strike a chord (and which do not). Under the leadership of the Canadian 
Box 3. Examples of alignments and strategies to foster population health intervention research during the early years of the Population Health Intervention Research Initiative for Canada

New funding streams created

New research career positions created within decision-maker partnerships (e.g. municipal governments, public health agencies)

New training investments in population health intervention research

New products and procedures in research development and knowledge translation

New collaboration to foster the field of population health intervention research internationally
- New 'rapid response' funding stream within Canadian Institutes of Health Research to evaluate new policy (e.g. tobacco pricing, transport route alterations, food retail outlet changes).

- Public Health Agency of Canada's Innovation Strategy: Taking Action to Reduce Health Inequalities in Canada.

- Built Environment: Population Health Intervention Research. Heart and Stroke Foundation of Canada, in partnership with the Canadian Institutes of Health Research: Institute of Circulatory and Respiratory Health; Institute of Human Development, Child and Youth Health; Institute of Musculoskeletal Health and Arthritis; Institute of Nutrition, Metabolism and Diabetes; and Institute of Population and Public Health.

- Applied Public Health Chairs, funded by Canadian Institutes of Health Research and the Public Health Agency of Canada.

- New 6-year training grants through Canadian Institutes of Health Research (Strategic Training in Interdisciplinary Health Research awards).

- Development of peer review guidelines for population health intervention research.

- Casebook on examples of population health intervention research.

- Special supplement to Canadian Journal of Public Health on population health intervention research.

- New associate editor position at the Canadian Journal of Public Health for intervention research.

- Joint meetings on population health intervention research with Medical Research Council (UK) and Economic and Social Research Council (UK).

- Joint conference on the science of community intervention research organised with the Centers for Disease Control (USA).
Institutes of Health Research's Institute of Population and Public Health a symposium and workshop in late 2010 also showcased intervention studies and spotlighted some of the debates on advancing the science of this field and building links with research in related fields (e.g. implementation systems and improvement science).

PHIRIC resisted having any formal priority areas early in its development, for fear that these might bow to pressure to mimic standard chronic disease domains, create 'winners and losers' in this process and potentially take PHIRIC away from a whole-system focus. This decision proved wise, allowing organisations at the PHIRIC table to follow their own priority concerns and develop stronger investment in intervention research in whatever domains resonated with their stakeholders and partners. Most likely, PHIRIC's strength will continue to come from strategies that have worked previously - that is, finding like-minded people and initiatives, building partnerships and opening up possibilities to consolidate resources.

The question of priorities has risen again recently. This time, system-focused priority areas have been readily embraced. The leading idea is that PHIRIC must create stronger system-level demand for population health intervention research. The unharnessed lever for the demand is public interest.

Right now, Canada is better at tracking the uneven distribution of Canadians' health problems than at accounting 
for this distribution, in part, by the uneven distribution of known effective solutions (both on the treatment and prevention side). ${ }^{19,20}$ Yet, where data systems within some authorities are strong, convincing causal stories can be made linking reminder systems with immunisation rates, ${ }^{21}$ mobile services with uptake of mammography ${ }^{21}$ and workplaces with comprehensive tobacco control policies with higher smoking quit rates among their employees. ${ }^{22}$

Hence, PHIRIC's newest vision is to prompt more public awareness about which preventive policies and programs are being routinely delivered to whom with what effects. Hopefully then the public may come to demand better preventive policies and programs with the same vigour they currently reserve for accessing health care. ${ }^{19,20}$ Increased public accountability would in turn prompt better investment in data systems across the sectors, to track the distribution of these policies and programs. Better data systems about delivery of or exposure to policies and programs that have the potential to improve health at the population level will in turn invite more research linking these exposures with outcomes and their distribution. This goal is now within PHIRIC's sights. This is just one aspect of population health intervention research, but one firmly in the interests of many partners.

\section{Conclusion}

It might be easy to think that PHIRIC is possible simply because of Canada's historic commitment to the field of population and public health research. While this provided one ready constituency to harness, we chiefly attribute the success of PHIRIC to its organisational form. PHIRIC is a loosely structured alliance that relies on no particular champion or funding stream, enabling each agency and group taking part to work out how to make their own agenda more 'PHIRIC-like'. For example, for a funder this means creating population health intervention research and training funding streams. For a health delivery agency it means making a stronger commitment to planning and evaluation. Both benefit from better intervention research review criteria and relevant options in knowledge translation. As such, PHIRIC fits the criteria of a 21 st century networked organisation. ${ }^{23}$ It is carried forward by many actors, it adjusts its shape to fit the circumstances, and it is powered by events and forums that bring supply and demand for intervention research together. This heterogeneity creates strength and allows vision beyond what each actor could achieve alone.

\section{Acknowledgments}

Erica Di Ruggiero is the Associate Director of the Institute of Population and Public Health at the Canadian Institutes of Health Research. Penelope Hawe and Stephen Samis are the founding co-chairs of PHIRIC. Penelope Hawe represented the Institute Advisory Board of the Canadian Institutes of Health Research Institute of Population and Public Health on the PHIRIC planning committee. Her term on the Board ended in August 2010 and her role was taken by Jeannie Shoveller. Penelope Hawe is a Health Scientist of the Alberta Heritage
Foundation for Medical Research (now called Alberta Innovates Health Solutions). Jeannie Shoveller is an Applied Public Health Chair, Canadian Institutes of Health Research and a Senior Scholar of the Michael Smith Foundation for Health Research. We thank the people and organisations whose work is reflected in PHIRIC's achievements. We thank Nancy Edwards, Scientific Director, Canadian Institutes for Health Research, Institute for Population and Public Health, for her comments on an early draft.

For more information on PHIRIC please contact Erica Di Ruggiero: e.diruggiero@utoronto.ca

\section{References}

1. Canadian Institute for Advanced Research. Available from: www2.cifar.ca

2. Evans RG, Stoddart GL. Producing health, consuming health care. Soc Sci Med 1990; 31(12): 1347-63. doi:10.1016/02779536(90)90074-3

3. Evans RG, Barer M, Marmor TR, editors. Why Are Some People Healthy and Others Not? The Determinants of Health of Populations. New York: Walter de Gruyter, Inc; 1994.

4. Raphael D, Bryant T. The limitations of population health as a model for a new public health. Health Promot Int 2002; 17(2): 189-99. doi:10.1093/heapro/17.2.189

5. Labonte $\mathrm{R}$. The population health/health promotion debate in Canada: the politics of explanation, economies, and action. Crit Public Health 1997; 7: 7-27. doi:10.1080/09581599708409075

6. Milward L, Kelly M, Nutbeam D. Public health intervention research: the evidence. London: Health Development Agency; 2001.

7. Di Ruggiero E, Rose A, Gaudreau K. Canadian Institutes of Health Research support for population health intervention research in Canada. Can J Public Health 2009; 100(Suppl.): I15-9.

8. Population Health Intervention Research Initiative for Canada. ('PHIRIC') Workshop Report. 26-27 September 2006, Banff Centre, Banff, Alberta, Canada. Canadian Institutes for Population and Public Health. Institute of Population and Public Health. Available from: www.Canadian Institutes of Health Research-irsc.gc.ca/e/33515.html

9. Canadian Institutes of Health Research. Institute of Population and Public Health. Mapping and Tapping the Wellsprings of Health. Strategic Plan. 2002-2007.

10. Rose G. The Strategy of Preventive Medicine. Oxford University Press; 1992.

11. Butler-Jones D. Public health science and practice: from fragmentation to alignment. Can J Public Health 2009; 100(Suppl.): I1-4.

12. Sullivan L. Introduction to the Population Health Intervention Research Initiative for Canada. Can J Public Health 2009; 100(Suppl.): I5-7.

13. Hawe $\mathrm{P}$, Potvin L. What is population health intervention research? Can J Public Health 2009; 100(Suppl.): I8-14.

14. Riley BL, Stachenko S, Wilson E, Harvey D, Cameron R, Farquharson J et al. Can the Canadian Heart Health Initiative inform the Population Health Intervention Research Initiative for Canada? Can J Public Health 2009; 100(Suppl.): I20-6. 
15. Cameron R, Riley RL, Campbell HS, Manske S, Lamers-Bellio $\mathrm{K}$. The imperative of strategic alignment across organizations: the experience of the Canadian Cancer Society's Centre for Behavioural Research and Program Evaluation. Can J Public Health 2009; 100(Supp1.): I27-30.

16. Kendall P. Commentary on population health intervention research. Can J Public Health 2009; 100(Suppl.): I31-2.

17. Shiell A. The Population Health Intervention Research Initiative for Canada: an estimate of the return on investment. Population Health Intervention Research Centre, University of Calgary; September 2010 .

18. McCann JE. Design guidelines for social problem solving interventions. J Appl Behav Sci 1983; 19(2): 177-89. doi: $10.1177 / 002188638301900213$

19. Hawe P, Shiell A. Using evidence to expose the unequal distribution of problems and the unequal distribution of solutions. Eur J Public Health 2007; 17(5): 413. doi:10.1093/ eurpub/ckm095
20. Hawe P, Shiell A. Creating demand for a disease prevention and health promotion system. In: Roach R, editor. Alberta's Energy Legacy: Ideas for the Future. Calgary: Canada West Foundation; 2007.

21. Martens P, Fransoo R, The Need to Know Team, Burland E, Prior H, Burchill C et al. What Works? A First Look at Evaluating Manitoba's Regional Health Programs and Policies at the Population Level. Winnipeg: Manitoba Centre for Health Policy; March 2008.

22. Statistics Canada. Smoking bans. Influence in smoking prevalence. Health Rep 2007; 18(3): 9-24.

23. Weber EP, Khademian AM. Wicked problems, knowledge challenges, and collaborative capacity builders in network settings. Public Adm Rev 2008; 68: 334-49. doi:10.1111/ j.1540-6210.2007.00866.x 